\title{
Corporate Social Sustainability Relationship Management Practices-A Literature Review
}

\author{
Siddam Rao V N ${ }^{* \star}$ and Prof. G.V.Chalam^^ \\ \#Research Scholar, ^Department of Commerce \& Business Administration, Acharya Nagarjuna University, Nagarjuna Nagar-522 510. Andhra Pradesh, \\ India
}

Received 05 July 2018, Accepted 08 Sept 2018, Available online 11 Sept 2018, Vol.6 (Sept/Oct 2018 issue)

\begin{abstract}
Sustainability practices are increasingly prevalent in corporations and their institutional landscape. Over several years, organizations have been seeking for guidelines on sustainability, in terms of economic, environmental and social perspective. The corporate managements believe that sustainability is important for future success and growth and is interested in blending it with its day-to-day business strategy. Like all other new strategy implementations in an organization, sustainability implementation needs close monitoring and careful execution and management of sustainability initiatives dealing closely with its stakeholders. This paper aims at tracing sustainability issues in stakeholders' relationship management by discussing the theoretical approach is complemented with the sustainability issues by reviewing the earlier studies made so far. Apart from this, it also aims at to identify the research gap to undertake the further empirical research on the corporate social sustainability relationship management in the Indian context.
\end{abstract}

Keywords: Sustainability, Sustainability Relationship, Stakeholders, Corporate Social Responsibility, Corporate Social Sustainability, Local Community, Social Equity

Introduction

Sustainability refers to an organization's activities, typically considered voluntary, that demonstrate the inclusion of economic, social and environmental concerns in business operations and in interactions with stakeholders (van Marrewijk and Verre, 2003). It is the program and process in any organization woven into the social fabric of the community through broad-based interest, involvement and investment in the fulfillment of the corporate mission and vision. The program and process involve a complete network of individuals, stakeholders and business partners investing their time and resources for the purpose.

Philosophically, sustainability focuses on relationship management and development rather than just as a management. There are tasks that must be accomplished to develop and implement a sustainability plan. But fundamentally, sustainability is about developing, nurturing and managing various relationships. In Sustainability Relationship, building a strong stakeholder network becomes a valued and mission-critical asset for any organization. Sustainability is viewed as a continuous

*Corresponding author's ORCID ID: 0000-0001-9568-5978 DOI: https://doi.org/10.14741/ijmcr/v.6.5.3 journey rather than a destination. This research argues in favor of recognition of corporate social sustainability as both a normative and analytical concept. Of late, sustainability has been used more in the sense of human sustainability on planet earth. But this is only one aspect of sustainability. It has many situations and contexts depending on many scales of space and time.

\section{Three E's of Sustainability}

Three E's" of sustainability are: Economy, Ecology, and Equity. Unlike conventional notions of sustainability that are linked to environmentalism and dwell only in the ecology sector, this three-pronged approach considers the fact that all "three Es" are interconnected.

\section{Three Pillars of Sustainability}

The three main pillars of sustainability are environmental sustainability, social sustainability and economical sustainability. However, there is an overlap between these pillars; economical sustainability depends on social sustainability and social sustainability depends on the environmental sustainability. These three pillars are not mutually exclusive. 


\section{Three Spheres of Sustainability}

The Brundtland Report provided tripartite conceptual framework by which to evaluate any action as truly sustainable, the so-called "three Es" of sustainability: Environment, Economy, and Equality. The three interrelating spheres that represent sustainability in the most complete sense of the word are shown below:

This triple bottom line approach is also represented as people, planet and profit.

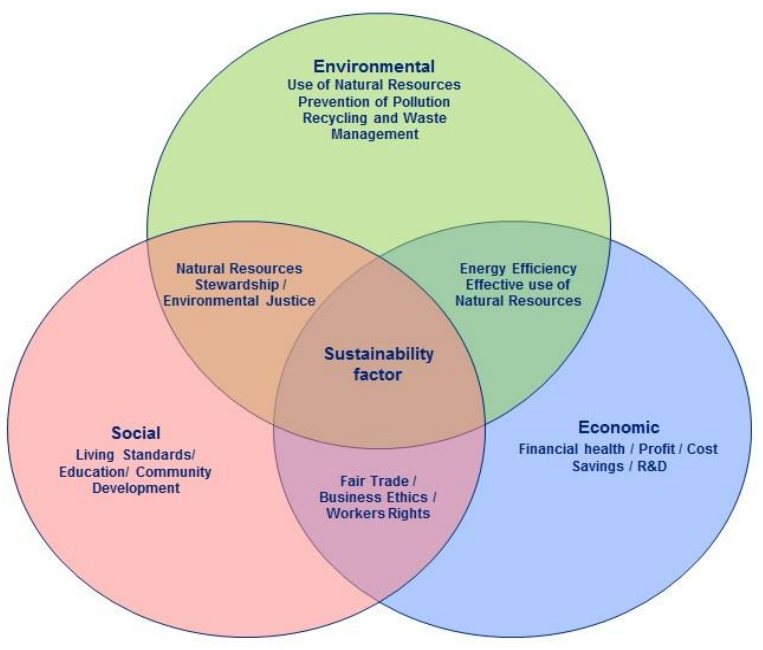

Figure-1 Three Spheres of Sustainability

\section{Challenges of Modern Corporates}

Air and water pollution, sanitation, poverty, unemployment, child labor, corruption are just a few challenges that corporate businesses face regularly. Until recently, most of the corporations thought that sustainability meant financial profits for the company. Lately companies recognized that it is not the case and they should now consider the other two pillars of sustainability. The challenge is on how and what to integrate and synchronize for the corporate sustainability efforts. How to be more environmentally and socially responsible and engage the stakeholders more effectively. What specific actions the management can take to effectively deal with the problem of how to improve corporate environmental and social performance while maintaining the financial performance.

The pressure for implementing the corporate programs to integrate the environmental, economic and social sustainability is increasing. Managements have now recognized the importance of stakeholders input and engagement for long-term corporate sustainability. Thus, the relationship between the Management and Stakeholders is crucial. Still many large, medium and small industries have not developed any strategies around sustainability concepts. Some if not many companies which have negative opinion and developed none or partial systems of sustainability programs have started paying the price. Certain companies which have commitment to implement but failed in integrating these programs are looking into more effective systems to include sustainability in everyday decision-making process. Achieving sustainability is a huge task and continuous process which needs aggressively proactive effort.

\section{Corporate Sustainability Relationship Management}

Social sustainability can be achieved through social mobilization. By doing business companies have an effect on their neighbors, customers and the economic vitality of the entire region. There are many simple steps that a company can take to improve the lives of people in its community, including volunteer projects and contributions to charitable organizations and interest groups. Stakeholders or Business partners for a corporate business house are partner companies, Investors, specialist organizations, Government, workers and employees' groups and the general public associated directly or indirectly with the business of the company.

Sustainability is multidimensional. There are several key areas an organization has to begin exploring stakeholders to develop relationships. Though the list is not all exhaustive, business and industry, non-profit organizations, education, religious congregations, healthcare services, government, civic service or activist organizations etc., can be considered as a starting point for developing corporate sustainability relationships. The company reports to and learns from its stakeholders to assess the company's performance and aspirations on the sustainability.

\section{Corporate Social Responsibility (CSR) and Corporate Social Sustainability (CSS)}

There is a difference between Corporate Social Responsibility (CSR) and Corporate Social Sustainability (CSS). Corporate Social Sustainability encompass strategies and practices that aim to meet the needs of stakeholders, while seeking to protect, support, and enhance the human and natural resources that will be needed in the future, while Corporate Social Responsibility is the continuing commitment by business to behave ethically and contribute to economic development while improving the quality of life of work force and their families as well as a local community and society at large. Corporate Social Responsibility focuses more on non-financial societal activities that a company can contribute whereas Corporate Social Sustainability focusses both on impact of environmental factors on the company and company impact on environment.

\section{Background}

Thus, the social sustainability has become an issue for the public and the private sector in recent years. Many 
problems associated with social injustice, slavery, child labor, racial discrimination, unsafe workplaces, etc., are covered under national, regional and local regulations. Companies develop programs for sustainability implementation as per the policies and the regulations. There are a number of issues to consider regarding the implementation of these programs. Constant review and evaluation of those strategies and programs need close monitoring. Stakeholders undertake this implementation effort based on the costs, time, processes etc., Stake holders are groups and individuals with a common interest in an organization progress. Shareholders, investors, employees, communities, etc., look into the financial, environmental and social wellbeing of the company. Sustainability stakeholders include internal stakeholders, viz: Employees, Management, Shareholders, Suppliers, Contractors and other Service providers and external stakeholders include Business to Business clients, International Clients, Research Organizations, NGOs, Government Agencies, Statutory Bodies, Activists and Local communities.

In this paper an attempt is made to review the earlier studies made on corporate social sustainability relationship management to identify the research gap. The need and rationale of the study are also discussed at the end.

\section{Review of Literature}

This literature review is not an add-on but an integral part of any research. There are not many benchmarks set forth at the time of writing this paper. As the concept of corporate social sustainability itself is in its emerging stages, the context of the subject establishes a ground work for the overall scope of this study. Further this review justifies the reason for conduct research and focuses on the theoretical framework.

Marc J. Epstein's (2008) "Implementing Corporate Sustainability, Measuring and Managing Social and Environmental Impacts", the question of whether or why organizations should pay attention to issues of social and environmental responsibility is no longer up for discussion. The challenge is how this responsibility needs to be carried out. As corporates search for ways to improve their performance, determining the best approaches to thoroughly integrate the social concerns into all parts of company operations still causes challenges. These challenges exist because implementing sustainability programs is fundamentally different from implementing other strategies in the organization. For sustainability, the goal is to achieve excellence in the social and financial performance. Managing and measuring this creates significant challenges. When there is a significant financial cost involved in improving social performance, managers often face dilemma of how to make the choices and what actions to take.

$\mathrm{He}$ also opined that the benefits can best be measured over long time horizons only. There is a constant uncertainty on how much such sustainability efforts are necessary and how far long-time horizons are necessary to measure these benefits. To improve the integration of social and environmental impacts into dayto-day management decisions, companies must tie the measurement and reporting of these impacts into decision-making processes. Further, they must measure and report these impacts in financial terms and then integrate them into the traditional investment models. Some companies have developed comprehensive selfassessment programs to focus their organization's efforts on performance areas that create value for the company's stakeholders and that help sustain long-term improvements. Other companies have tied individual performance reviews and compensation explicitly to sustainability performance, establishing social and environmental performance as a critical variable for compensation in incentive systems. Many companies haven't focused on quantifying the link connecting sustainability actions, sustainability performance, and financial gain and haven't focused on making the "business case" for corporate social responsibility. Instead, they act in socially responsible ways because they believe it's "the right thing to do."

Margot J. Hutchins, John W. Sutherland (2010) expressed in their attempt that an exploration of measures of social sustainability and their application to supply chain decisions that while the Brundtland definition of sustainability is widely known as a starting place in constructing a definition for sustainability, rigorous definitions for corporate social responsibility and social sustainability have yet to be established. There are strong linkages between the concepts of sustainability and CSR. Many definitions of CSR include references to ethical behavior related to the environment, society, and the economy. One principle of CSR is conducting business in a way that is consistent with the morals and values of society, but "not necessarily required by law". Some have argued that the only social responsibility of a business organization is to deliver profits to its owners/shareholders.

Ernst and Young (2010) in their report on media, events, and research collected by Green Biz compiled and opined that though this report concentrated on the stakeholder interest in corporate sustainability reporting, it came up with few distinct trends in the sustainability practices.

1) Sustainability reporting is growing, but the tools are still developing

2) The Chief Financial Officer (CFO's) role in sustainability is on the rise

3) Employees emerge as a key stakeholder group for sustainability programs and reporting

4) Despite regulatory uncertainty, greenhouse gas reporting remains strong, along with growing interest in water

5) Awareness is on the rise regarding the scarcity of business resources 
6) Rankings and ratings matter to company executives.

Darcy Hitchcock and Marsha Willard (2010), in their study, the stakeholders are categorized into four broad groups to consider for sustainability aspects: They are:

- Employees (and the labor pool) in the workplace

- Suppliers

- Customers of products or service

- Members of the community in which the industry operates.

They tried an attempt on corporate sustainability relationship programs and raised two primary questions for social sustainability - what people need, how to use the information to assess social sustainability in organizations?

- First, do no harm - In what ways are we undermining these needs for our stakeholders?

- Second, make a positive difference - How can we contribute to meeting these needs in a sustainable way?

Julia Ruedig and Anisa Baldwin Merzger (2010) in their study on "managing organizational sustainability titled the Business Case for Sustainability Professionals in the workplace" concludes that unlike sales staff, whose performance can be directly measured by volume of sales, sustainability personnel find it more difficult to define success in their role. Sustainability roles are highly collaborative, complicating the method for attributing a positive result to any one position. A single, straightforward method for measuring the effectiveness of sustainability personnel across the board may not be possible. Further, there is a lack of research that spotlights sustainability managers and their link to sustainability performance. By providing a better understanding of sustainability staff roles, relevant performance metrics and keystone functions of sustainability staff, this report provides preliminary direction for the next step in linking sustainability staff to organizational sustainability performance.

In a study on leadership and accountability for the 90s, titled "Business strategies for Sustainable Development", published in 1992 by the International Institute for Sustainable Development in conjunction with Deloitte \& Touché, suggested that the two main areas of the management system that must be changed are those concerned with:

a) Greater accountability to non-traditional stakeholders;

b) Continuous improvement of reporting practices.

It proposed seven steps that are required for managing an enterprise according to sustainable development principles. (a) Perform a stakeholder analysis

(b) Set sustainable development policies and objectives

(c) Design and execute an implementation plan

(d) Develop a supportive corporate culture

(e) Develop measures and standards of performance

(f) Prepare reports

(g) Enhance internal monitoring processes

Eric Krell and Jessica Fries (2010) in their piloted study on the corporate sustainability programs found that these activities are evolving, and companies and their executives are increasingly recognizing the importance of sustainability to the future of their businesses. While many corporate sustainability initiatives began because organizations felt they had to fulfill in response to compliance requirements and that they should have them in support of corporate value statements, more organizations now want to deploy sustainability programs to reap greater shareholder value. Rather than treating sustainability efforts exclusively as a response to legal and regulatory requirements, more organizations are now integrating sustainability activities into how they manage reputation risk, generate cost savings and ensure longterm profitability and competitive advantage.

Corporate sustainability programs are also expanding in number across the spectrum of company size and industry sector. No longer solely the domain of the smokestack industry or large multinational conglomerates, organizations of all types and sizes are increasingly implementing sustainability programs and practices. Key findings show that large companies have more robust sustainability capabilities than small companies, the finance function's contributions to organizational sustainability programs are highly valued, yet underdeveloped. Measuring sustainability elements like energy usage, employee well-being progress and greenhouse gas emissions reductions is important because these measurements serve as the foundation of an effective sustainability report. Corporate sustainability programs mainly focused on energy usage, water usage, employee well-being programs and recycling. Finally, the study results suggest that sustainability marks a 'very strong driver' of employee engagement and indicate that the company's sustainability programs positively influence their decision to do business.

Basiago, A.D. the Environmentalist (1999), says that the criteria for a paradigm of social sustainable development as elaborated by Kahn (1995) are Equity, Empowerment, Accessibility, Participation, Sharing, Cultural Identity and Institutional Stability. Social sustainability implies a system of social organization that alleviates social conditions such as poverty. The theory of 'social sustainability' often calls for economic growth constrained by the requirements of social equity. Some of 
the dependable means to achieve Social sustainability are;

- View natural resources as limited in nature

- Cultivate the lushness of the settlement area

- Stress equitable distribution over production

- Rely on information, not machinery

- Establish deliberative decision process

- Value family community over individuals

- Work for enjoyment rather than avoiding toil

- Cherish folk life rather than entertainment

- Reduce family size and resource use

- Eliminate divisions of clan, caste, class

- Practice gender-neutral opportunity policies

- Strive for universal education of population

- Address disparities in economic attainment

- Level the economic playing field for all

- Make all citizens economic stake-holders

- Sponsor land reform to give land to its tillers

- Subsidize food, health care, and education

- Work deliberately to use resources efficiently

- Address 'wellness needs' of the population

- Meet 'wellness needs' on an all-for-one basis

Stephen McKenzie defined social sustainability as a condition, by measuring it with a series of indicators. Social sustainability is a life-enhancing condition within communities, and a process within communities that can achieve that condition. The following features are indicators of the condition, and steps towards their establishment and implementation are aspects of the process:

- equity of access to key services (health, education, transport, housing and recreation)

- equity between generations, meaning that future generations will not be disadvantaged by the activities of the current generation

- a system of cultural relations in which the positive aspects of disparate cultures are valued and protected, and in which cultural integration is supported and promoted when it is desired by individuals and groups.

- the widespread political participation of citizens not only in electoral procedures but also in other areas of political activity, particularly at the local level

- a system for transmitting awareness of social sustainability from one generation to the next

- a sense of community responsibility for maintaining that system of transmission

- mechanisms for a community to collectively identify its strengths and needs
- $\quad$ mechanisms for a community to fulfil its own needs where possible through community action

- mechanisms for political advocacy to meet needs that cannot be met by community action.

UNEP/SETAC (United Nations Environment Program/The Society of Environmental Toxicology and Chemistry) in the framework for social impact categories, on similar lines as Stephen McKenzie social sustainability indicators, and apart from G4 GRI Guidelines, has provided quantitative, qualitative and semi-quantitative form organized according to key stakeholder groups (Workers, Local Communities, Consumers, Society and Value Chain Actors). Among these groups, subcategories of assessment have been defined.

Table-1: UNEP/SETAC Framework for Social Sustainability Impact Categories

\begin{tabular}{|c|c|}
\hline Stakeholder Group & Impact Category \\
\hline Workers & $\begin{array}{c}\text { - Freedom of Association and Collective } \\
\text { Bargaining } \\
\bullet \text { Child Labour } \\
\bullet \text { Fair Salary } \\
\text { - Working Hours } \\
\bullet \text { Forced Labour } \\
\text { - Equal Opportunities/Discrimination } \\
\text { - Health and Safety } \\
\text { - Social Benefits }\end{array}$ \\
\hline Consumers & $\begin{array}{l}\text { - Health and Safety } \\
\text { - Feedback Mechanism } \\
\text { - Consumer Privacy } \\
\text { - Transparency } \\
\text { - End of Life Responsibility }\end{array}$ \\
\hline Local Community & $\begin{array}{c}\text { - Access to Material Resources } \\
\text { - Access to Immaterial Resources } \\
\text { - Delocalization and Migration } \\
\text { - Cultural Heritage } \\
\text { - Safe and Healthy Living Conditions } \\
\text { - Respect of Indigenous Rights } \\
\text { - Community Engagement } \\
\text { - Local Employment } \\
\text { - Secure Living Conditions }\end{array}$ \\
\hline Society & $\begin{array}{l}\text { - Public Commitments to Sustainability Issues } \\
\text { - Contribution to Economic Development } \\
\text { - Prevention and Mitigation of Armed Conflicts } \\
\text { - Technology Development } \\
\text { - Corruption }\end{array}$ \\
\hline Value Chain Actors & $\begin{array}{c}\text { • Fair Competition } \\
\text { - Promoting Social Responsibility } \\
\text { - Supplier Relationships } \\
\text { - Respect of Intellectual Property Rights }\end{array}$ \\
\hline
\end{tabular}

ISO 26000 framework indicators also contain a wide range of background information on social responsibility that is useful for constructing enterprise-specific inventory indicators with Organizational Governance, Human Rights, Labour Practices, The Environment, Fair 
Operating Practices, Consumer Issues and Community Involvement and Development.

Table-2: ISO 26000 Framework Indicators

\begin{tabular}{|c|c|}
\hline Organizational Governance & Social Responsibility indicators \\
\hline Human Rights & $\begin{array}{c}\text { - Organizational Governance } \\
\text { • Due Diligence } \\
\text { - Human Rights Risk Situations } \\
\text { - Avoidance of Complicity } \\
\text { - Resolving Grievances } \\
\text { - Discrimination and Vulnerable } \\
\text { Groups } \\
\text { - Civil and Political Rights } \\
\text { - Economic, Social and Cultural } \\
\text { Rights } \\
\text { - Fundamental Principles and Rights } \\
\text { at Work }\end{array}$ \\
\hline Labour Practices & $\begin{array}{l}\text { - Employment and Employment } \\
\text { Relationships } \\
\text { - Conditions of Work and Social } \\
\text { Protection } \\
\text { - Social Dialogue } \\
\text { - Health and Safety at Work } \\
\text { - Human Development and Training } \\
\text { in the Workplace }\end{array}$ \\
\hline The Environment & $\begin{array}{l}\text { - Prevention of Pollution } \\
\text { - Sustainable Resource Use } \\
\text { - Climate Change Mitigation and } \\
\text { Adaptation } \\
\text { - Protection of the Environment and } \\
\text { Restoration of Natural Habitats }\end{array}$ \\
\hline Fair Operating Practices & $\begin{array}{c}\text { - Anti-corruption } \\
\text { - Responsible Political Involvement } \\
\text { - Fair Competition } \\
\text { - Promoting Social Responsibility in } \\
\text { the Sphere of Influence } \\
\text { - Respect for Property Rights }\end{array}$ \\
\hline Consumer Issues & $\begin{array}{l}\text { - Fair Marketing, } \\
\text { - Factual and Unbiased Information } \\
\text { - Fair Contractual Practices } \\
\text { - Protecting Consumers' Health and } \\
\text { Safety } \\
\text { - Sustainable Consumption } \\
\text { - Consumer Service, Support } \\
\text { - Complaint and Dispute Resolution } \\
\text { - Consumer Data Protection and } \\
\text { Privacy } \\
\text { - Access to Essential Services } \\
\text { - Education and Awareness }\end{array}$ \\
\hline $\begin{array}{l}\text { Community Involvement } \\
\text { and Development }\end{array}$ & $\begin{array}{c}\text { - Community Involvement } \\
\text { - Education and Culture } \\
\text { - Employment Creation and Skills } \\
\text { Development } \\
\text { - Technology Development and } \\
\text { Access } \\
\text { - Wealth and Income Creation } \\
\text { - Health } \\
\text { - Social Investment }\end{array}$ \\
\hline
\end{tabular}

Pepperdine's set of indicators of social sustainability are:

- Social which includes sense of Future, Sense of community or belonging, community activities, even age structure,
- Human which includes Even age structure, Economic viability,

- Institutional which includes Political representation, Economic viability, Employment opportunities, Meeting places,

- Produced which include Economic viability, Employment opportunities Meeting places, and

- Natural which includes economic viability, employment opportunities.

The framework used is clearly very efficient in measuring the strengths and weaknesses of an individual community according to a detailed set of indicators. Such data would be useful in determining the most appropriate planning measures to increase social sustainability within the community.

\section{Research Gap}

From the foregoing review of the attempts made so far by various experts in this field, it can be seen that social sustainability programs are a complex phenomenon. It can be said that the factors affecting these programs have never been examined empirically in a single study, without a well-developed, comprehensive theoretical model for social sustainability. It also needs to be seen how companies can benefit by addressing social and environmental issues, which can in turn attract more investments from public and thus motivate employees are also not focused in any of the said studies. Further, no attempt was made so far to how corporate reputation can benefit significantly if the company can act with responsibility to the society and how new market avenues open up for the corporations, if the social sustainable relationships are taken care of. To reap all these gains the organizations, as a part of their business, need to understand how they can contribute to various social sustainable development programs.

\section{Rationale of the Study}

Sustainability planning strengthens partnerships by creating greater clarity about the long-term results. Corporate management need to make a sustainability perspective business case or more specifically 'A societal case'. A good sustainability societal case plan allows activities like resource development and public relations to be carried out in a way that not only meets short-term needs but also positions the initiative for long-term success. Social sustainability is a part of a broader societal agenda which extends beyond the organization. Social sustainability is an independent dimension of sustainable development. It is important but still lacks broad recognition by research thinkers as well as by decision makers. Social sustainability is best dealt with to include the social implications of environmental issues. Social 
sustainability encompasses human rights, labor rights, and corporate governance.

\section{Conclusion}

Against this background and also by identifying the gap of the research, an attempt is made is to be made to explore the programs and practices in corporate sustainability relationships with its stakeholders and how these trends contribute to corporate value creation. More specifically, the aim of further research is to look into stakeholders' relationships, partners' involvement in the sustainability programs in the select industrial organizations. Further, the study should also focus on how the corporate management can establish communications with its stakeholders in the process for attaining corporate sustainability. Last, it should also demand for a comprehensive look into many issues in the field of Corporate Sustainability Relationship Management (CSRM).

\section{References}

[1]. Making Sustainability Work, Mark J. Epstein, Berrett Koehler Publishers, Second Edition, 2014

[2]. Making Sustainability Work: Best Practices in Managing and Measuring Corporate Social, Environmental and Economic Impacts (January 2008) by Greenleaf Publishing in the U.K. and by Berrett-Koehler Publishers in the U.S.

[3]. Alessia D'Amato, Sybil Henderson, Sue Florence, Corporate Social Responsibility and Sustainable Business - A Guide to Leadership Tasks and Functions, Center for Creative Leadership, New Jersy.

[4]. Tracy Bhamra and Vicky Lofthouse, Design for Sustainability, Gower Publishing Limited Croft Road, Hampshire, GU11 3HR England.

[5]. Thomas Dyllick1 and Kai Hockert, Beyond the Business Case for Corporate Sustainability, John Wiley \& Sons, Ltd and ERP Environment, 2002.

[6]. Kevin Jones and Jennifer L Bartlett, The Strategic Value of Corporate Social Responsibility: A Relationship Management Framework for Public Relations Practice, Lucid Communications, Queensland University of Technology, 2009
[7]. Ionela Carmen Pirnea, Marieta Olaru, Cristina Moisa, Relationship between corporate social responsibility and social sustainability, Bucharest Academy of Economic Studies, Bucharest, Romania.

[8]. Reporting Principles and Standard Disclosures. G4 Sustainability Reporting Guidelines. 2013 Global Reporting Initiative., www.globalreporting.org, Amsterdam, Netherlands. Updated on 5 August 2015.

[9]. Margot J. Hutchins, John W. Sutherland, An Exploration of Measures of Social Sustainability and their Application to Supply Chain Decisions, Sustainable Futures Institute, Michigan Technological University, USA. Published by Elsevier Ltd. 2011.

[10]. Carroll AB. The pyramid of corporate social responsibility: toward the moral management of organizational stakeholders. Business Horizons 1991

[11].Julia Ruedig and Anisa Baldwin Merzger, Managing Organizational Sustainability: The Business Case for Sustainability Professionals in the Workplace, , The Center for Green Schools at the U.S. Green Building Council, McGraw Hill Financial Global Institute.

[12]. Evolution of Corporate Sustainability Practices Perspectives from the UK, US and Canada, Eric Krell and Jessica Fries (2010) for CIMA, CICA, and AICPA research study.

[13]. Manufacturing Sector in India, IBEF: India Brand Equity Foundation Report, 2015

[14]. Krishna H. Shukla and Nitin U. Dwivedi, Sustainable development in agricultural sector in India, The Business \& Management Review, Vol. 5(4), January 2015.

[15].BASIAGO, A.D., Economic, social, and environmental sustainability in development theory and urban planning practice, The Environmentalist 19, 145]161 1999, 1999 Kluwer Academic Publishers, Boston. Manufactured in the Netherlands.

[16].Social indicators of rural community sustainability, The Gilbert Valley, South Australia in Cocklin and Alston, originally from S Pepperdine (used by Peter Smiles and Graeme Hugo).

[17]. Social sustainability practices in the supply chain of Indian manufacturing industries Venkatesh Mani University of Porto, Rajat Agrawal Indian Institute of Technology Roorkee. 